\title{
18으 CICAM
}

Congresso de Iniciação Científica em Ciências Agrárias, Biológicas e Ambientais

Resumo 04

DOI: $10.31368 / 1980-6221 \mathrm{c00042020}$

EFICIÊNCIA DE PRODUTOS BIOLÓGICOS NO CONTROLE DE Meloidogyne incognita EM CAFÉ CV. ARARA*. BRUNO V.N. ${ }^{* *} ;$ ROSA, J.M.O. ${ }^{2}$; OLIVEIRA, C.M.G. ${ }^{2 * *}{ }^{1}$ Pontifícia Universidade Católica de Campinas, Faculdade de Ciências Biológicas, Campinas, SP, Brasil. E-mail: victornbruno@hotmail.com Instituto Biológico, ${ }^{2}$ Centro Avançado de Pesquisa em Proteção de Plantas e Saúde Animal/CAPSA, Laboratório de Nematologia, Alameda dos Vidoeiros 1097, CEP 13101-680, Campinas, SP, Brasil. Efficiency of biological products in the control of Meloidogyne incognita in coffee cv. Arara.

O café é um produto altamente comercializado e exportado pelo Brasil. Dentre os problemas fitossanitários que afetam o cafeeiro, os nematoides são responsáveis por um dos maiores prejuízos econômicos. Como alternativa sustentável de controle, o presente projeto de iniciação científica teve como objetivo testar em condições de casa de vegetação a eficácia do fungo Metarhizium anisopliae no controle biológico do nematoide das galhas Meloidogyne incognita em café cv. Arara. O experimento foi inteiramente ao acaso, com 5 tratamentos e 4 repetições. Parcela constituída de uma planta por vaso de 5,0 litros, contendo substrato autoclavado. Após o transplante da muda de café cv. Arara, cada planta foi inoculada com 5.000 ovos de M. incognita. Os tratamentos foram aplicados ao redor de cada planta, contendo o fungo $M$. anisopliae, provenientes da coleção mantida no Laboratório de Controle Biológico/CAPSA, IB, e o produto comercial Rizotec ${ }^{\circledR}$ (Pochonia chlamydosporia, cepa Pc 10). Dez meses após a inoculação, observou-se que $\operatorname{Rizotec}^{\circledR}(0,45 \mathrm{~g} /$ planta) apresentou $81,12 \%$ de eficiência na redução da população de $M$. incognita, com 0,6 de fator de reprodução (FR), já M. anisopliae, na porção de 0,06g/ planta, apresentou $73,25 \%$ eficiência na redução da população de $M$. incognita e $F R=0,9$. Os resultados permitiram concluir que os agentes biológicos são promissores na ação bionematicida.

${ }^{* *}$ Bolsista CNPq. 